artigo ] voLume 10 | NÚMERO 21 | MAIO 2017

[MARCIA DE SOUZA BORGES]

Doutoranda em Educação pela Universidade Estácio de Sá; professora e coordenadora dos cursos de graduação e pósgraduação em Design de Moda da Universidade Estácio de Sá.

E-mail: marciaclosouza@gmail.com

\title{
Problematizando a formação superior em Moda
}

\section{Questioning fashion higher education}

[resumo] 0 presente artigo propõe reflexões acerca da formação em Moda no Brasil, buscando relacionar essa educação com um predominante direcionamento dos cursos para o mercado de trabalho. Esse pensamento é oriundo de experiências na área de moda, nos universos profissional e acadêmico e também fruto de uma pesquisa de mestrado já finalizada, que apenas ilustra o presente texto. Este artigo apresenta também breve histórico sobre a formação em Moda, a conexão entre design e Moda na formação superior e a moda como área de atuação. 0 objetivo é buscar entender a formação em Moda e as formas de interação entre as Instituições de Ensino Superior e o mercado de trabalho.

\section{palavras-chave}

\section{moda; formação superior; atuação de}

mercado.

[abstract] This article aims to reflect about the fashion studies in Brazil, seeking to relate the fashion higher education with a possible targeting for the work in the fashion industry. This issue comes from an experience in the fashion field, both professional and academic universes, also the knowledge acquired with an already completed master's research, which only illustrates the present text. It also presents a brief history about fashion training, the connection between design and fashion in higher education and fashion as an area of work activity. The goal is to understand the training in fashion and the forms of interaction between Higher Education Institutions and the fashion industry.

[keywords] fashion; higher education; market performance. 


\section{Introdução}

Não é de hoje que a área de Educação, em especial no ensino superior, observa e propõe a importância de se criar currículos integrados com objetivos educacionais dinâmicos, organizados em eixos de conhecimento que possam consolidar um sujeito generalista, moldável, adaptável e estrategista. Mais do que isso, atualmente, propõe-se, também, desenvolver competências que possam ir ao encontro dos anseios que o mercado tem sobre o trabalho dos egressos dos cursos superiores. Como resultado, as novas tendências educacionais reconhecem o estudante como o centro do processo ensino-aprendizagem e, de acordo com isso, devem contribuir para o seu crescimento e o seu desenvolvimento social e profissional. Assim, na vida adulta, fica latente a necessidade de uma relação do futuro do aluno com o conteúdo e a aplicação desse conhecimento em sua vida profissional.

Essa necessidade de relação entre o conteúdo e a aplicação do conhecimento na prática cotidiana, em determinados cursos, pode provocar uma ideia equivocada de formação apenas para desempenho de competências e habilidades práticas. Entretanto, é de conhecimento comum que as possibilidades de sucesso de uma carreira não são determinadas apenas pelo preparo técnico de seus profissionais. A importância da formação geral, com uma bagagem de conhecimento sólido sobre determinada área, vai permitir flexibilidade conceitual para mudar estratégias, conforme as necessidades das atividades diárias (SORCINELLI, 2008). No que diz respeito à formação em Moda, parece existir uma complexidade no entendimento do que vem a ser uma formação adequada para o perfil do profissional dessa área.

Parece oportuno, nesse momento em que a formação em Moda vem ganhando espaço em todo o Brasil e no exterior, poder entender o papel da formação superior em Moda. Embora essa formação venha crescendo de forma representativa no cenário do ensino superior, como poderá ser verificado a seguir, aumentam, também, os debates em torno dela, em especial sobre seu direcionamento mercadológico, como se a formação em moda não pudesse ir além disso, o que poderia acabar privilegiando o fazer perante o saber.

\section{Breve olhar sobre o surgimento da formação em Moda}

A formação superior em Moda é algo recente no Brasil. Começa na Faculdade Santa Marcelina, pioneira ao oferecer o curso de graduação na área, em 1987. Na sequência, vem a Universidade Anhembi Morumbi, em 1990, e, no mesmo ano, a Universidade Paulista, todas na cidade de São Paulo (PIRES, 2002).

Antes dos cursos universitários de moda, o desenvolvimento da profissão do estilista, como era conhecido o profissional que trabalhava com moda no Brasil, não exigia formação superior. Como apresentado por Aguiar (2015, p. 3),

[...] no Brasil, a Moda não era vista como uma área para ser estu-

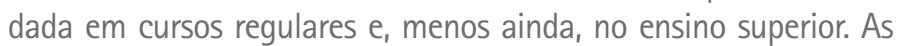
peças de roupas eram copiadas das tendências internacionais - e era esse 0 atrativo das roupas - para que as pessoas as comprassem como produtos diferenciados, sendo vendidas como "a última Moda em Paris". 0 que se ditava lá fora era aceito aqui, como acontece até hoje, provavelmente, pela tradição na área que os países europeus têm, frente ao Brasil.

Assim, os que assumiam a carreira eram autodidatas, sem formação específica, que aprendiam o ofício com o exercício da profissão (PIRES, 2002). Desse modo, restava a impressão de que bastava ter bom gosto, algum talento artístico e um pouco de informação sobre moda para ser um profissional da área. De certa forma, se o objetivo era reproduzir, podia ser que essa impressão estivesse correta 
e suficiente. Assim, ficava o entendimento que apenas gostar já era o suficiente para atuar, não havendo a necessidade de preparação ou estudo mais aprofundado para o desempenho da profissão.

Com o passar dos anos, a área da moda brasileira iniciou um processo de qualificação de seus profissionais. Antes do surgimento dos cursos superiores, nos anos 1980, a Casa Rodhia passou a oferecer um curso de criação e estilismo. Segundo Pires (2002), esse foi o primeiro curso na modalidade regular com métodos diferenciados, que tinha preocupação em criar peças exclusivas e não focava apenas em corte e costura.

A autora ainda coloca que, com o aumento de empresas têxteis e de confecção no país, nos anos 1980, a moda começou a ser tratada como área de negócio. Com o incremento da economia e de empresas do setor, sentiu-se a necessidade de se criar cursos especializados na área a fim de formar profissionais para suprir a demanda do mercado. Assim, a formação em Moda começou a consolidar seu escopo de curso voltado para a área do fazer, especialmente direcionada para o desenvolvimento do vestuário.

Segundo Marinho (2005), o surgimento dos cursos superiores em São Paulo teve como cenário o amadurecimento da indústria têxtil e de confecção, o que exigia dos candidatos aos empregos disponiveis mais qualificação, necessitando assim de maior conhecimento dentro do campo da moda. Além disso, a sociedade, dada a abertura de mercados, tornou-se mais ávida por bens simbólicos ${ }^{1}$. Marinho (2005) ainda aponta para a constituição de uma classe média urbana no pais, que foi se desenhando cada vez mais significativa, não só respondendo pela demanda dos bens produzidos pela indústria, mas também pelo consumo de informação, moldando um novo padrão de gosto estético. Concomitante a esses acontecimentos, houve ainda a expansão do ensino superior privado que proporcionou a diversificação da oferta de cursos.

Esse cenário, apresentado em meados dos anos 1980, tem nos dias atuais um espelho de acontecimentos que também explica a atual inserção da moda de forma mais representativa no contexto acadêmico. Hoje, 35 anos depois, a moda segue o mesmo percurso, com foco cada vez maior nas possibilidades de atuação do profissional, consolidando a necessidade desses cursos prepararem para o mercado de trabalho.

\section{A formação superior em Moda}

A formação superior nessa área vem passando por muitas transformações que buscam solidificar a moda como um campo de conhecimento. Contudo, a visão de formar um profissional para atuar no mercado de trabalho deixa a impressão de que essa formação deve, em especial, desenvolver habilidades técnicas para o fazer, o que pode acabar enfraquecendo a necessidade da formação superior, uma vez que habilidades técnicas podem ser adquiridas em cursos técnicos, cursos livres ou em outros cursos de nivel intermediário. No contexto universitário, mesmo a formação tecnológica, preferida na área da moda, deveria também buscar fornecer aos alunos embasamento teórico, técnico-científico, artístico e cultural, com foco no empreendedorismo e no desenvolvimento sustentável. Dessa forma, seria capaz de formar profissionais aptos a participar, de forma estratégica, criativa e operacional das atividades relacionadas à área da moda em geral, valorizando a formação humana mais ampla.

Para Anchieta (2010, p. 6), o profissional de moda não apenas deve saber representar ideias, transformando desenhos em produtos, mas deve "saber retratar os desejos específicos de cada tribo". Mais do que isso, "deve entender a Moda na sua totalidade interpretando no produto as expectativas e desejos contemporâneos" (ibidem). Conforme observado por Torres (2010, p. 73 e 74): 
0 entendimento dos comportamentos que impulsionam o mercado consumidor passa por uma equipe multidisciplinar, bem como por múltiplos conceitos e ferramentas metodológicas provindos de diversas áreas. Pressupor um código comum e compartilhado pelos clientes e empresas ao desenvolverem seus produtos, pós-pesquisa de mercado, faz com que exista sucesso de venda após o longo caminho normalmente percorrido em relação aos atos comportamentais do momento. É por meio deste código comum que os resultados das pesquisas são transferidos ao mercado, atendendo as necessidades e desejos dos clientes.

Dessa forma, pode-se perceber que a complexidade da profissão está em perceber o momento histórico analisado, com todas as suas caracteristicas, e traduzi-lo, e estar atento às diversidades, analisar o mercado e o seu consumidor específico, seus anseios e desejos, e a partir daí concretizar o projeto por meio desse conhecimento amplo e divulgá-lo no veículo direcionado ao seu público-alvo.

Consciente ou inconscientemente, a moda desempenha um papel importante na vida das pessoas. Muito além do vestuário, está presente na vida em sociedade: na interação social, nas mais simples tarefas cotidianas, nos comportamentos, na observação ou não dos códigos do vestir, na arquitetura, na linguagem ou em várias outras formas de manifestação. Assim, estar preparado para atuar na área da moda requer conhecimento multidisciplinar para conseguir mover-se, especialmente, no âmbito de três questões fundamentais que o profissional da área deve responder: o que é preciso produzir, quem vai consumir e como será distribuído. Responder a estas questões requer atributos que vão além do fato de poder reproduzir produtos de consumo.

Para melhor entender a formação superior em Moda é relevante situar a educação superior no âmbito do mundo do trabalho. É sabido que nem sempre a universidade teve objetivo de formar para exercer uma profissão. Na Idade Média, por exemplo, a educação era um instrumento para se alcançar a sabedoria e, esta, poderia levar à felicidade. A felicidade era o bem mais perfeito almejado pela sociedade (AL-FARABI, 2002). Com o passar dos tempos, com a organização das sociedades, as revoluções e a instalação do capitalismo, essa visão muda e a universidade se direciona para "gerar saber de nível superior para viabilizar 0 funcionamento da sociedade" (BUARQUE, 1994, p. 117). Claro que, conforme a sociedade, esse papel se apresenta de forma diferente.

Nos Estados Unidos a universidade desempenhou uma função-chave na construção da sociedade de consumo, na defesa da potência econômica e militar norte-americana. Na África do Sul, a universidade branca serviu competentemente para viabilizar a elevação do nível de vida dos brancos e manter o sistema do apartheid funcionando. Em países da Europa, as universidades são instrumentos de dinâmica de economia. Através do mercado, elas conseguem oferecer mão-de-obra e pesquisas para consumidores e empresas. (lbidem, p. 117)

Trazendo essa reflexão para a esfera do ensino superior de Moda, seria interessante poder observar o direcionamento que as universidades dão para essa formação, uma vez que a falta de posicionamento pode desprender um efeito dominó que culmina em algo abrangente, chamado generalista, mas que pode acabar não servindo nem para o mercado, nem para uma dimensão humanis$t a^{2}$, por falta de aprofundamento nos conhecimentos recebidos, predominando a abrangência e a superficialidade. 
Os cursos de Design de Moda, mais do que outras formações em âmbito universitário, têm relações estreitas com a formação profissionalizante, mesmo em nivel superior. Basta uma simples procura pelos currículos oferecidos nos cursos superiores de Moda, disponibilizados na internet, para perceber uma grande ênfase na dimensão prática, que busca atender às demandas emergenciais da cadeia têxtil e de confecção, privilegiando o projeto, a criação, o desenho e a modelagem de roupas e acessórios do vestuário (BISNETO; PEREIRA, 2013). 0 problema, contudo, não está em oferecer um curso profissionalizante na esfera superior, e sim em não ter um posicionamento específico, um posicionamento pensado para oferecer programas e rotas de articulação com o mercado de trabalho na área almejada, que possa promover um processo educativo menos produtivista e mais transformador. Para Morin (2004 apud CARNEIRO, 2015, p. 464), um dos desafios do século XXI é precisamente:

[...] organizar a educação profissional para oferecer cursos, programas e rotas de articulações diversificadas, trabalhando com o conhecimento e habilidades que classificam adequadamente os alunos-cidadãos e os cidadãos-alunos para a cidadania produtiva, o mundo do trabalho e o mercado de trabalho.

Claro que não se pode esquecer que essa educação, mesmo adequada aos tempos atuais, voltada para a vida produtiva, "deve superar os limites acanhados e estreitos" da educação apenas para o mercado de trabalho e do conhecimento prescrito para atividades operacionais. Não deve ser uma educação "para o trabalho", mas ter um direcionamento para um conhecimento de produção de vida com possibilidade de transformação da vida no trabalho (CIAVATTA, 2015, p. 72).

Apesar desse entendimento, Carneiro $(2015$, p. 465) fala sobre uma dificuldade de diálogo entre a academia e o mundo empresarial:

[...] os educadores brasileiros e a própria academia dificultaram sempre o diálogo entre o mundo empresarial e a escola. Com isto, inviabilizava-se o currículo focado em competências, como se o trabalho produtivo não possuisse uma natureza social.

Sobre a ideia de competência, ressaltada por Carneiro, vale juntar o entendimento de Kuenzer $(2003$, p. 1$)$ que fala da "capacidade de atuar mobilizando conhecimentos", que podem ser tácitos e científicos, e que serão somados a todas as outras experiências do indivíduo na busca de solucionar problemas "em situações previstas e não previstas" (ibidem). Não é uma visão simplista de atender ao mercado, mas sim uma capacidade de articular conhecimentos multidisciplinares, teóricos e práticos, que somados podem diminuir a vulnerabilidade do individuo, aumentando a confiança e incitando à ação.

A falta de diálogo entre academia e mundo de trabalho, ressaltada por Carneiro, por vezes, pode fazer com que os cursos, apesar de aparentemente focados no mundo do trabalho, acabem direcionados para desenvolver habilidades específicas para a reprodução de tarefas daquilo que se acredita ser o dia a dia do designer/estilista, especialmente, de produtos do vestuário, esvaziando a possibilidade do egresso de refletir sobre novas formas criativas e sustentáveis de intervir em processos já fossilizados da indústria da moda, deixando de cumprir com um princípio importante da formação superior que é:

[...] conhecer e disponibilizar conhecimentos capazes de dar conta de princípios, formulações e metodologias no âmbito de processos de formação humana [...] estimular o desenvolvimento do espírito científico 
que supõe não só equipar os alunos com os instrumentos intelectuais necessários para uma leitura adequada do mundo, mas também compor blocos de atividades de conhecimentos e de indagação acadêmica, possibilitando o intercâmbio de ideias em ambientes de informação totalmente abertos. (CARNEIRO, 2015, p. 505)

Apesar da expansão do ensino de moda no Brasil nos últimos 35 anos, que claramente acompanha o crescimento do setor, a moda não é considerada uma área, ou mesmo uma subárea específica, pelo Ministério da Educação (MEC) e não apresenta diretrizes curriculares próprias. Nos documentos e legislações, os cursos de graduação em Moda estão inseridos na área de Design, seguindo a Resolução CNE/CES n. 5, de 8 de março de 2004 (BRASIL, 2004), que aprova as Diretrizes Curriculares Nacionais do Curso de Graduação em Design. Com isso, a ênfase nas universidades brasileiras é para uma formação voltada à produção, à gestão e à inovação tecnológica, ou seja, às características mercadológicas.

Também há o mesmo direcionamento para a formação do tecnólogo. No Catálogo Nacional dos Cursos Superiores de Tecnologia, elaborado pelo MEC em cumprimento ao Decreto n. 5.773, publicado em julho de 2006 (BRASIL, 2006), os cursos superiores de Tecnologia (CST) em Moda são alocados dentro do eixo de Produção Cultural e Design. Eles são denominados Design de Moda e apresentam como objetivo o desenvolvimento e a gerência de projetos para a indústria de confecção do vestuário.

Percebe-se, especialmente no Catálogo Nacional dos Cursos Superiores de Tecnologia, um privilégio do desenvolvimento e do gerenciamento de projetos para a área do vestuário, o que evidencia um entendimento da moda relacionado com roupa, até mesmo pelos órgãos reguladores.

Essa aproximação do design e da moda não se deu de forma fácil. Dorotéia Pires, uma das pesquisadoras que mais contribuíram para as reflexões e pesquisas sobre o ensino de Moda, Design e Design de Moda no Brasil, afirmou em entrevista que os cursos de Moda passaram gradativamente a ajustar-se aos conceitos do design.

Na década de 1980, ainda não existiam publicações, eram raros os pesquisadores interessados pela área e a indústria compreendia esta atividade apenas como estilística, era a pré-história do design de Moda. Não existia conexão entre design e Moda, esta consolidação foi se dar somente em 2000 quando o MEC determinou que: os cursos de estilismo deveriam passar a denominar-se design de Moda. Hoje, o Brasil é o país com o maior número de cursos em todo o mundo. [...] Agora precisamos superar este valor quantitativo e traçar estratégias para crescer a qualidade tanto na dimensão acadêmica quanto na empresarial. Este é um grande desafio, uma vez que o setor trabalha de modo individualizado e fragmentado, isto é, não tem percepção de unidade entre a indústria, academia, varejo, centros de pesquisa, editoras, feiras, entre outros. Deveríamos pensar de modo sistêmico. (ASSINTECAL, 2008)

Considerando os dados de 2013 do INEP/MEC, o Brasil possui 136 cursos com a nomenclatura Design de Moda (sendo 32 bacharelados, 103 cursos superiores de Tecnologia e um de licenciatura); 38 cursos de Moda (sendo quatro CST, três sequenciais, 31 bacharelados); e mais três outros com diferentes nomenclaturas: Têxtil e Moda; Design e Estilismo; Design Industrial - Design de Moda, totalizando 177 cursos de nível superior.

Os números apresentados acima, que colocam o Brasil como o país com a maior quantidade de cursos de graduação em Moda no mundo (UNIVERSIA, 
2013), não mostram na atuação dos profissionais oriundos dessa formação o mesmo panorama promissor. Ao contrário, o que é possivel perceber é que mesmo professores e egressos demonstram certo desapontamento quanto às possibilidades de atuação profissional nessa área (BORGES, 2014).

Esse entendimento - de que, apesar da formação específica, os egressos oriundos dos cursos de formação em Moda têm dificuldade para inserção no mercado de trabalho na área - foi constatado em minha dissertação de mestrado. 0 trabalho, que teve como tema Representações sociais de alunos e professores do curso de Design de Moda sobre a Moda, apresentou em suas conclusões o desapontamento, em especial dos alunos concluintes, com as possibilidades de inserção nesse mercado tão amplo, de números expressivos e, ao mesmo tempo, restrito para a atuação profissional. Os relatos da maioria dos formandos e professores deixaram claro esse sentimento. Embora vejam o diferencial da formação específica, parecem acreditar que a atuação na área é uma ilusão (BORGES, 2014).

Ainda com relação à dissertação citada, ficou nítida a dificuldade de definição do objeto de estudo da área, a moda, reforçando que esta dificuldade é oriunda das suas várias possibilidades de abordagem: teórico-prática, mercadológica, sociológica, artística, entre outras. Além disso, ficou evidente que a moda ainda carrega olhares pejorativos, especialmente no ambiente acadêmico. Os sujeitos deixaram transparecer que a sociedade vê a moda como algo de mulher, lugar para quem lida com luxo e futilidades. Esse tipo de concepção, além de incomodar os atores que vivenciam as realidades desse campo de atuação, pode afugentar os aprofundamentos acadêmicos, prevalecendo a visão de superficialidade da formação em Moda, direcionando o curso de Design de Moda para um caminho de formação de segunda classe.

Outro ponto apresentado na dissertação que incitou a continuidade das pesquisas foi a dificuldade que alunos e professores de moda tiveram para materializar a moda como objeto. Os termos que emergiram desse trabalho, "mutação" e "multiplicidade" (BORGES, 2014, p. 79), evidenciaram a falta de materialização do objeto, uma vez que as próprias palavras dão a ideia de algo instável ou "não concreto" (ibidem). Isso confirma o fato de que existe um obstáculo em lidar com assuntos como a moda, mesmo que no âmbito acadêmico. Além disso, sua característica de volubilidade, talvez por causa das exigências do mercado, deixa as pessoas inseguras para se prenderem em conceitos, principalmente quando a prioridade é o produto. Pode ser que a rapidez, acompanhada de mudanças, não dê muito tempo para o aprofundamento teórico. Contudo, enquanto forma de interação, articuladora de movimentos de consumo e de relações econômicas, a Moda precisa ser entendida para, assim, poder ser estudada.

A área da Moda, exatamente por um perfil multitarefas, pode acabar por não delinear de forma concreta o conjunto de habilidades desejadas do profissional que nela vai atuar. Esta falta de direcionamento, por vezes, tende a fazer com que a formação seja mais generalista para que possa haver maior aderência de conhecimentos ao cargo futuramente pretendido pelo aluno. Esse perfil de curso, quando confrontado com a realidade de mercado de trabalho, pode deixar seus profissionais inseguros para a atuação, inclinados a responsabilizar a formação superior pela falta de direcionamento, ou mesmo por uma inadequada interface (instituição-mercado de trabalho).

Assim, parece pertinente, nesse momento, contrastar aquilo que é proposto no campo do conhecimento, inclusive pela legislação vigente que rege o exercício da prática, e a realidade pedagógica existente nas instituições de ensino. Pesquisas no Brasil e no exterior ${ }^{3}$ têm mostrado que, apesar de muitas vezes satisfeitos com os cursos de Moda, suas disciplinas e seus professores, alunos pelo mundo inteiro estão insatisfeitos com a relação entre os cursos que frequentam e a prática da profissão. 
Em alguns casos, talvez por causa de um entendimento equivocado da palavra moda, alguns cursos ainda direcionem seus alunos, durante a formação, para área de criação de vestuário, sem refletir de forma mais assertiva sobre as várias outras possibilidades de atuação. Esse entendimento fica evidenciado nas grades curriculares disponíveis nos sites das instituições, nos quais há a predominância de estudos voltados para o vestuário, sem observar as especificidades da região na qual são oferecidos, limitando a atuação do designer de moda ao ato de fazer roupa.

\section{Moda: as multidimensões da área}

0 termo moda apresenta múltiplas formas de análise, sua abrangência propõe diálogos entre áreas aparentemente distantes, mas que são extremamente complementares. Para Garcia e Miranda (2005, p. 109):

De modo geral, psicólogos veem a moda como busca da individualidade; sociólogos compreendem-na como competição de classe e conformidade social às normas; economistas explicam-na pela busca do escasso, do que é difícil de conseguir; criadores observam a visão estética, os componentes artísticos e o ideal de beleza; historiadores oferecem explanações evolucionárias para as mudanças da moda. Entretanto, a moda em processo não pode ser vista apenas sob determinada ótica.

Nesse sentido, conforme proposto por Bisneto e Pereira (2008, p. 405), a multiplicidade de olhares da moda evidencia a amplitude do campo de conhecimento, "alertando para a necessidade de compreendê-la enquanto fenômeno social e humano gerador de numerosos bens de consumo, objetos-signos e imagens, nas sociedades contemporâneas".

Ainda segundo os mesmos autores, "as diversas dimensões da moda deveriam ser observadas de forma integrada, em um todo capaz de constituir um pensamento sistêmico da moda, partindo do pensar moda para então fazer moda" (ibidem). A ideia é que entendendo o fenômeno e sua dimensão, seja possivel perceber seus aspectos de adoção e consumo pela sociedade. Assim, pode-se buscar oferecer bens culturais, objetos e signos, materiais e imateriais, funcionais ou não, com valores estéticos e/ou emocionais, capazes de manter um elo de comunicação social.

Complementando esta visão, Castilho $(2004$, p. 109) observa que a moda como um sistema abstrato de criação, produção e difusão de bens de consumo, também pode ser entendida como "um conjunto de comportamentos significativos que exprimem os valores próprios de uma época e tramitam juntamente com essa determinada época". Assim, para se fazer moda, antes é preciso entender a moda.

\section{A moda como área de trabalho}

A área da moda tem forte expressão nos mercados nacional e internacional e é um dos grandes pilares econômicos. No Brasil, segundo os dados da Associação Brasileira da Indústria Têxtil e de Confecção - ABIT (2016), a moda é o segundo maior empregador da indústria de transformação, perdendo apenas para a de alimentos e bebidas (juntos). É também a segunda maior geradora do primeiro emprego. 0 Brasil é o quinto maior produtor têxtil do mundo, o segundo maior produtor e terceiro maior consumidor de denim ${ }^{4}$; o maior produtor e consumidor de moda praia; o quarto maior produtor de malhas; e o quarto maior parque produtivo de confecção. Tem, também, a única cadeia têxtil completa do Ocidente: só o Brasil tem desde a produção das fibras, como a plantação de algodão, até os desfiles de moda, passando por fiações, tecelagens, beneficiadoras, confecções e 
forte varejo. Além disso, produz uma moda reconhecida: a moda brasileira está presente entre as cinco maiores Semanas de Moda do mundo. 0 quadro abaixo apresenta os principais dados econômicos do setor têxtil:

\section{Quadro 1- Dados econômicos do setor têxtil}

\begin{tabular}{|c|c|}
\hline $\begin{array}{l}\text { Faturamento da cadeia têxtil e } \\
\text { de confecção }\end{array}$ & US\$ 36,2 bilhões contra US\$ 53,6 bilhões em 2014. \\
\hline $\begin{array}{l}\text { Exportaç̃es (sem fibra de } \\
\text { algodão) }\end{array}$ & US\$ 1,08 bilhão contra US\$ 1,18 bilhão em 2014. \\
\hline $\begin{array}{l}\text { Importações (sem fibra de } \\
\text { algodão) }\end{array}$ & US\$ 5,85 bilhões contra US\$ 7,08 bilhões em 2014 . \\
\hline $\begin{array}{l}\text { Saldo da balança comercial (sem } \\
\text { fibra de algodão) }\end{array}$ & $\begin{array}{l}\text { US\$ } 4,8 \text { bilhões negativos contra US\$ 5,9 bilhões } \\
\text { negativos em } 2014 \text {. }\end{array}$ \\
\hline $\begin{array}{l}\text { Autossuficiente na produção de } \\
\text { algodão }\end{array}$ & $\begin{array}{l}\text { 9,4 bilhões de peças confeccionadas por ano (destas, } \\
\text { cerca de } 5,3 \text { bilhổes em peças de vestuário), sendo } \\
\text { referência mundial em beachwear, jeanswear e } \\
\text { homewear. }\end{array}$ \\
\hline Investimentos no setor & US\$ 749 milhões contra US\$ 1.091 milhão em 2014. \\
\hline Produção média de confecção & $\begin{array}{l}5,5 \text { bilhões de peças (vestuário + cama, mesa e } \\
\text { banho) contra 6,1 bilhões de peças em } 2014 .\end{array}$ \\
\hline Produção média têxtil & $\begin{array}{l}\text { 1,9 milhão de tonelada contra 2,2 milhões de } \\
\text { toneladas em } 2014 \text {. }\end{array}$ \\
\hline Trabalhadores & $\begin{array}{l}\text { 1,5 milhão de empregados diretos e } 8 \text { milhões } \\
\text { indiretos e efeito renda, dos quais } 75 \% \text { são mão de } \\
\text { obra feminina. }\end{array}$ \\
\hline Número de empresas & 33 mil empresas formais em todo o pais. \\
\hline Empregos & Representa $16,7 \%$ dos empregos \\
\hline
\end{tabular}

Fonte: Associação Brasileira da Indústria Têxtil e de Confecção (ABIT). Disponivel em: http://www. abit.org.br/cont/perfil-do-setor. Acesso em: 15 out. 2016.

Com base nesses números, pode-se concluir que, por conta de sua grande expressão, esse segmento acabe por precisar de crescimento e qualificação de mão de obra em vários niveis de oferta. Entretanto, os processos de profissionalização ainda são poucos e precários, dificultando a consolidação do profissional da área, como observado por Bisneto e Pereira (2008, p. 158).

Apesar de muitas citações sobre a expansão da participação do Brasil no cenário da Moda mundial, é notória a necessidade de maior atenção aos processos de profissionalização e consolidação deste segmento de negócio. A intuição, característica predominante no processo de crescimento de diversas empresas brasileiras, gradativamente, vem cedendo espaço para o desenvolvimento planejado e pautado na pesquisa mercadológica, na compreensão dos processos histórico, social e comportamental da Moda e nas técnicas fundamentadas de pesquisa, desenvolvimento, produção, comercialização e promoção dos bens deste setor.

Assim, como apontado pelos autores, essa indústria que cresceu muito baseada na "intuição", com o passar do tempo e com a globalização, que aumenta a concorrência e a necessidade de mais conhecimento, inovação e tecnologia, precisa de profissionais preparados para atuar de forma mais planejada, com perfil 
para pesquisa, desenvolvimento, produção e comercialização, mas que possam também atuar de forma autônoma, transformando o campo do trabalho.

A relevância econômica do setor e sua representatividade no Brasil foram os principais fatores para a expansão do ensino superior na área, como apresentado anteriormente. As propostas dos cursos, em sua maioria, são voltadas para as áreas práticas, do fazer, uma vez que, com um mercado ávido por produtos, a indústria reflete a necessidade de mais mão de obra.

Entretanto, é possível perceber um direcionamento para o vestuário de moda, como se a indústria de confecção fosse a única oportunidade de trabalho para 0 profissional da moda. Assim, ao mesmo tempo que os cursos superiores exibem um perfil generalista e amplo, que tentam apresentar as multidimensões da moda, também o fazem trabalhando quase que exclusivamente o produto do vestuário, correlacionando o futuro profissional de moda ao designer de roupas e ao estilista.

Apesar da expressividade do setor têxtil e de confecções, a moda também tem outras áreas importantes, como calçados, acessórios de moda e joias, que ajudam a consolidar o setor economicamente em todo o mundo, mas que ficam em segundo plano nos cursos de formação superior.

Com tantos direcionamentos para a formação desse profissional, fica a impressão de ser difícil compor, mesmo que em quatro anos (para os cursos de bacharelado), um conteúdo curricular que possa dar conta dessa formação. Resta, no entanto, a certeza da necessidade de pesquisas que busquem investigar a amplitude do campo epistemológico da moda, bem como suas interfaces com outras áreas do conhecimento, contribuindo com resultados para o fortalecimento de uma formação menos aligeirada, que possa melhorar as possibilidades de atuação do profissional que nela pretende atuar e que possa auxiliar na definição da identidade desse profissional.

Conforme colocado por Bisneto e Pereira (2008, p.173):

Se, nas dimensões sociológica, histórica, antropológica e filosófica, a moda carece de ampliação e desprendimento das abordagens reducionistas, consequentemente, nas dimensões econômica, mercadológica, tecnológica e produtiva, tal estratégia poderá apresentar resultados econômicos e reflexos sociais surpreendentes, ao romper o vínculo restrito entre a cadeia produtiva da moda e a cadeia produtiva têxtil e do vestuário, assim como, ao ampliar o campo de atuação do profissional da moda para além da área do design.

Observa-se, então, que a cadeia produtiva de moda não se restringe ao cenário têxtil e de confecções, mesmo que este seja o de maior expressão. Além disso, fortalecer a dimensão do pensarmoda por vias de conhecimentos mais profundos, pode promover melhores resultados econômicos, sociais e ambientais, fortalecendo o fazer moda, dinamizando as possibilidades de atuação do futuro profissional, melhorando também as possibilidades de reconhecimento social.

\section{Considerações finais}

Os cursos superiores de Moda apresentam grande crescimento de mercado. Entretanto, suas raízes, fundamentadas nas necessidades de formação para o mercado de trabalho, ainda predominam no seu direcionamento, seus entendimentos acadêmicos ainda se mostram fragilizados. Além disso, a formação em Moda também vivencia uma realidade de grandes índices de evasão. As razões que configuram esse panorama são muitas, assim, buscar entender inicialmente o que é ser um profissional na área de moda, o que se objetiva desta formação, 
como as instituições de ensino interagem com essas realidades e formatam seus cursos para essas necessidades, seus direcionamentos didático-pedagógicos, entre outras questões importantes, são desafios que se apresentam neste momento para os educadores da área.

A atuação profissional em moda, bem como a oferta de cursos superiores, só faz crescer, ao mesmo tempo que se observa uma insatisfação com a área de trabalho. Essas construções e reconstruções podem ter fortes implicações nas expectativas de alunos e professores em relação à formalização do conhecimento de moda, e, consequentemente, nas suas possibilidades de atuação, fortalecendo ou não a formação.

As práticas profissionais não são neutras, mas se constituem em complexos movimentos, orientando as condutas dos sujeitos a partir do sentido que dão a tudo que os rodeia. Assim, uma profissão carrega em si as marcas dos valores, normas, modelos, símbolos e tudo mais que constitui o espaço na dinâmica de uma dada totalidade social (MADEIRA, 2003). Se essas construções não forem boas, não há como a área se fortalecer, a tendência desse tipo de formação é se esvair ou não servir para seu propósito.

Procurar entender e alinhar os conhecimentos e as habilidades que devem ser desenvolvidos na formação superior na área da moda precisa ser um procedimento constante da academia, pois é fundamental buscar reconhecer os diálogos que se estabelecem entre academia e mercado de trabalho, especialmente na atualidade, quando se tem a consciência da necessidade de interagir, construir e reconstruir, se necessário. As investigações poderão evidenciar melhores formas de interação entre as Instituições de Ensino Superior, o mercado de trabalho e os ingressantes, favorecendo o amadurecimento do setor, melhorando os currículos e diminuindo a evasão.

Recebido em: 05/02/2017

Aprovado em: 08/03/2017 


\section{NOTAS}

De acordo com Pierre Bourdieu (1997), um bem simbólico se configura quando a um objeto artístico ou cultural é atribuido valor mercantil, sendo consagrado pelas leis do mercado ao status de mercadoria. Para esses objetos é formado um grupo consumidor, bem como um grupo produtor de bens simbólicos.

${ }^{2}$ Concepção ampla que busca valorizar o ser humano. Para Gramsci (1989, p. 121), a função do intelectual e da escola é mediar uma tomada de consciência do aluno que passa pelo autoconhecimento individual e tem a possibilidade de reconhecer "o próprio valor histórico". Não se trata apenas de um "doutrinamento abstrato", mas da possibilidade de educar um "futuro governante".

${ }^{3}$ Referência à pesquisa The business of fashion website: Is fashion education selling a false dream?. Disponivel em: <https://www.businessoffashion.com/articles/education/global-fashion-school-rankings-2015>. Acesso em: 15 out. de 2016

${ }^{4} \mathrm{~A}$ palavra denim surgiu na França, em torno do século XVII. É oriunda da expressão serge de Nîmes, em referência a um tecido produzido na cidade de Nîmes. Levi Strauss importou esse tecido para seus trabalhadores mineiros, nos Estados Unidos, no século XIX. Posteriormente, também chamado de brim, esse tecido rústico é tingido com anil (também chamado de indigo). Durante o tingimento, apenas os fios de urdume (longitudinal) são tingidos, mantendo o núcleo branco. Assim, com o atrito, as calças começavam a desbotar e, mais tarde, foram apelidadas de "blue jeans" (CATOIRA, 2006).

\section{REFERÊNCIAS}

AGUIAR, G. C. O. Cursos superiores de Moda no Brasil: regulamentações, evoluções e perspectivas. In: Anais do 11 Colóquio de Moda. São Paulo. 2015.

AL-FARABI. El camino de la felicidad. Traducción, introducción y notas R. Ramón Guerrero. Madri: Ed. Trotta, 2002.

ANCHIETA, A. A complexidade da moda como profissão. In: Anais do 6º Colóquio de Moda. São Paulo. 2010 .

ASSINTECAL - Associação Brasileira de Empresas de Componentes para Couro, Calçados e Artefatos. Disponivel em:<http://www.assintecal.org.br>. Acesso em: 30 jul. de 2015.

BISNETO, José Pereira Mascarenhas; PEREIRA, Sônia Elbachá. Gestão ou design de vestuário? 0 ensino da Moda na Bahia. In: Revista Gestão e Planejamento. Salvador, vol. 14, n. 1, pp. 157-176, jan./abr. 2013.

BORGES, Marcia de Souza. Representações sociais de alunos e professores do curso de Design de Moda sobre a Moda: 2014. Dissertação (Mestrado em Educação) - Curso de Educação, Universidade Estácio de Sá, Rio de Janeiro, 2014.

BOURDIEU, P. A estrutura invisível e seus efeitos. In: Sobre a televisão. Rio de Janeiro: Jorge Zahar Editor 1997, pp. 55-120.

BRASIL Lei 9.394, de 20 de dezembro de 1996, que "fixa diretrizes e bases da educação nacional". Diário Oficial da União. Brasília, n. 248, 23 dez. 1996.

. Ministério da Educação. Educação superior: cursos e instituições. Disponivel em: <http://www. educaçaosuperiorinep.gov.br>. Acesso em: 15 fev. 2015.

Resolução CNE/CES n. 5, de 8 de março de 2004, que aprova as Diretrizes Curriculares Nacionais do Curso de Graduação em Design. Disponivel em: <http://portal.mec.gov.br>. Acesso em: 20 nov. 2014.

Catálogo Nacional dos Cursos Superiores de Tecnologia. Disponivel em: <http://portal.mec.gov. br>. Acesso em: 20 jun. 2016.

BUARQUE, Cristovam. A aventura da universidade. São Paulo: Editora Universidade Estadual Paulista; Rio de janeiro: Paz e Terra, 1994

CARNEIRO, Moaci Alves. LDB fácil: leitura crítico-compreensiva. Ed. 23. Rio de Janeiro:Vozes, 2015.

CASTILHO, Káthia. Moda e linguagem. São Paulo: Anhembi Morumbi, 2004.

CATOIRA, Lu. JEANS: roupa que transcende a moda. Ed. 2. São Paulo: Ideias \&t Letras, 2006.

CIAVATTA. Maria. A historicidade da pesquisa em educação profissional. In: SCARELI, G. (org.). Educação, culturas, políticas e práticas educacionais e suas relações com a pesquisa. Porto Alegre: Sulina, 2015, pp. 62-83.

GARCIA, Carol; MIRANDA, Ana Paula Celso de. Moda é comunicação: experiências, memórias, vinculos. São Paulo: Anhembi Morumbi, 2005. 
GRAMSCI, Antonio. Os intelectuais e a organização da cultura. Trad. Carlos Nelson Coutinho. Ed. 7. Rio de Janeiro: Ed. Civilização Brasileira, 1989, 244 p. (Perspectivas do homem. Série Filosofia, vol. 48).

KUENZER, A.Z. Competência como práxis: os dilemas da relação entre teoria e prática na educação dos trabalhadores. In: Boletim técnico do SENAC. Rio de Janeiro, vol. 29, pp. 17-27, 2003.

MADEIRA, M. C. Representações sociais e educação: importância teórico-metodológica de uma relação. In: MOREIRA, A. P.; JESUíNO, J. C. (org.). In: Representações sociais: teoria e prática. Ed. 2 rev. João Pessoa: Universitária UFPB, 2003, pp.123-144.

MARINHO, Maria Gabriela S.M.C. Ensino Superior de Moda: condicionantes sociais e institucionalização acadêmica em São Paulo. Uma abordagem histórica. In: Moda, comunicação e cultura - Um olhar acadêmico. São Paulo: Arte \&t Ciência, 2005

PIRES, Dorotéia B. A história dos cursos de design de Moda no Brasil. In: Revista Nexos: Estudos em comunicação e educação. Especial Moda. São Paulo: Universidade Anhembi Morumbi, ano 6, n. 9, 2002. Disponivel em: <http://www.inovacaoedesign.com.br/artigos_cientificos/db_historia_escola_design_ Moda_1_.pdf. . Acesso em: 22 ago. 2012.

SORCINELLI, Paolo (org.). Estudar a Moda: corpos, vestuários, estratégias. São Paulo: Senac, 2008.

SOUZA, C. S. M.; NEIRA, L G.; BASTIAN, W. Regulação do ensino do design de Moda - para quem? In: PCtD DESIGN - Congresso Brasileiro de Pesquisa e Desenvolvimento em Design, 9, 2010. São Paulo. Anais. São Paulo: Universidade Anhembi Morumbi / AEND |BRASIL, 2010.

TORRES, A. C. C. Representações sociais de alunos e professores do curso de moda sobre o mercado consumidor: 2010. 104 p. Dissertação (Mestrado em Educação) - Curso de Educação, Universidade Estácio de Sá, Rio de Janeiro, 2010.

UNIVERSIA. Disponivel em: http://estudos.universia.net/brasil/curso/area/artes-humanidades-artes-Moda>. Acesso em: 8 jun. 2013. 